This manuscript is a non-peer reviewed preprint submitted to EarthArXiv.

\title{
International Meeting 40 years of the 1980 Azores Earthquake, 6th - 7th October 2020 - Conference Report
}

Fontiela, João ${ }^{1^{*}}$,

Bezzeghoud, Mourad ${ }^{1}$

Oliveira, Carlos Sousa²

Ferreira, Mónica Amaral ${ }^{2}$

Nunes, João Carlos ${ }^{3}$

${ }^{1}$ Instituto de Ciências da Terra - Universidade de Évora

${ }^{2}$ Instituto Superior Técnico, CERIS, Universidade de Lisboa

${ }^{3}$ Universidade dos Açores

* ifontiela@uevora.pt

\begin{abstract}
The main goal of the International Meeting "40 Years of the 1980 Azores Earthquake" was promoting a reflection of the earthquake of January $1^{\star}, 1980$, and the advances since them on topics like seismology, seismic hazard, and risk, building rehabilitation and public policies. Nevertheless, due to the COVID-19 outbreak, the organizing committee decided that the meeting should be online and rearrange the strategy, reduce the scientific program, and canceled the social one. The scientific program had five sessions, with six keynotes, 16 presentations, round table beyond the opening ceremony. All the sessions were live-streamed and available at https://azores4080meeting.wordpress.com as well as the proceedings and program. Instituto Superior Técnico, Universidade dos Açores and Universidade de Évora handled the organization of the conference.
\end{abstract}

Keywords: Seismology, Crustal Structure; Seismic Hazard and Risk; Terceira Earthquake; Azores,

\section{Conference Report}

On January 1^, 1980, at 16h41 (GMT), an earthquake of M 7.2 (Richter) caused heavy damage to the building stock of Terceira, São Jorge, and Graciosa Islands, with epicenter in-between those islands. The social and economic impacts were high considering 61 death toll, hundreds of injuries, and thousands of homeless. The event was a milestone to the instrumental seismology of the Azores Islands, but also on the reconstruction policies. At the time of the earthquake, three seismic stations were operating in the Azores. After the mainshock, the director of the geothermal project decided to dismantle the temporary seismic network operating in São Miguel and deployed the seismic stations in the islands affected by the earthquake to monitor the seismic sequence (pers. communication Victor Hugo Forjaz). The Regional Government decided at the time that the reconstruction should start as soon as possible giving preference "to the so-called "self-construction" in which the main players were the owners of the houses to whom construction material was distributed and given some simple rules for an earthquake resistance procedure" (Oliveira and Ferreira, 2020). These authors stated that the regional authorities were concerned with the maintenance of the general appearance of the city and assuring a minimum of resistance to the seismic loads of the re-building stock. Three years later, UNESCO classified Angra do Heroísmo historical centre as a World Heritage Site, proof of careful reconstruction. The authors also highlight several aspects deemed of more importance and how we can take the lessons got from all these years to increase the resilience against future events that may occur not only in the Azores Islands but also in Portugal Mainland. 
Udías and Bufforn (2020) presented a review of the studies about the seismotectonics of the AzoresGibraltar region from the beginning of the $20^{\text {th }}$ century until now, emphasizing the main advancements toward a more comprehensive model of the Triple Junction where the Azores Archipelago is located.

The application of optical fiber telecom cables to monitor offshore earthquakes in the Azores region was one of the emergent topics presented at the meeting. Matias et al. (2020) depicted the advantages of the application of technologies like Distributed Acoustic Sensing (DAS), Photonics for Earthquake Monitoring (PEM) and Science Monitoring and Reliable Telecommunications (SMART) applied to different zones in the Azores Archipelago and the east of Gloria Fault. The first two technologies were evaluated concerning the gain in earthquake monitoring (GAP), taking into consideration the GAP required to obtain the earthquake location with a minimum of quality. DAS was evaluated considering earthquakes in the Azores Central Group and PEM to earthquakes located between Faial and Flores Islands. The evaluation of the gain obtained with SMART technology for Tsunami Early Warning to the sector east of the Gloria Fault was also presented.

The crustal structure study was approached by Ferreira et al. (2020a, Ferreira et al., 2020b), on crustal structure and earthquakes in the Azores; and by Hamak et al. (2020, unpublished work), on the threedimensional crustal image of Arraiolos (Alentejo region, Continental Portugal) using aftershocks sequence that followed the mainshock occurred on January 15, 2018 at 11:51 UTC in Aldeia da Serra in the Northeast of Arraiolos.

The record of historical earthquakes in the Azores starting back in the $15^{\text {th }}$ century and its magnitude stood with large uncertainties mostly due to the lack of studies using historical seismicity. Morais et al. (2020) presented an approach for the estimation of the magnitude of historical earthquakes: a sensitivity study of the 1980 and 1998 earthquakes in the Azores. The method uses fragility functions that describe the likelihood of exceeding a certain damage grade, based on the probability theory. Coupled to these probability models is the Bayes Theorem to update the prior magnitude model into a posterior magnitude distribution.

Gather faster feedback from users after experiencing an earthquake is of paramount importance to estimate macroseismic intensity. With this goal in mind, the Portuguese Institute for Sea and Atmosphere (IPMA) implemented the web questionnaire "Did you feel an Earthquake" and its automatic evaluation (Marreiros et al., 2020) on their seismic processing routine. This service accomplishes with the need to provide seismic information to the Civil Protection services after an earthquake is felt and feed the earthquakes database of the Portuguese Seismological Service. Another function of the questionnaire is to feed the ShakeMap tool to produce constrained maps of the seismic intensity distribution.

Loss estimate after an earthquake is fundamental to Civil Protection deploy the rescue teams in the most affected zones. In the Azores region, the rescue operations after a strong earthquake could be difficult, due to the intervention delay of the rescue teams amongst the different islands (Fontiela et al. 2020). Rosset et al. (2020) estimate losses using QLARM (Quake Loss Assessment for Response and Mitigation) for hypothetical earthquakes, one inland and the other offshore of a small volcanic island. To predict losses in volcanic areas is a challenging due to the lateral geological heterogeneities. Nevertheless, QLARM was able to estimate losses to the 1980 and 1998 earthquakes with high level of confidence and for the two scenarios.

The composite materials for civil engineering structures and their potential use in seismic areas was presented (Correia et al., 2020). The author showed the importance of the application of carbon fiberreinforced polymer in structural strengthening and seismic retrofitting, as well as on concrete columns connections reinforced with glass fiber-reinforced polymer bars (GRFP), connections and frames profiles, and sandwich panels made of GRFP. The last one is used to replace old building floors. 
One emergent topic is the impact of large earthquakes during COVID-19 outbreak. Silva (2020a, 2020b) studied the impacts to Continental Portugal for two earthquakes, one located on the offshore (Mw 8.7) and the other one onshore (Mw 5.7). The authors argue that for the largest earthquake is inevitable the rise on the number of COVID-19 cases while on the moderate earthquake the number of infect people is negligible since the impacts are managed rapidly and efficiently.

The 40180 Meeting included also a special discussion session structured as roundtable discussion to reflect on the 40 years after the 1980 earthquake. It had the participation of a Historian, President of the Azores Regional Assembly at the time of the earthquake, a volcanologist and an engineer. Local journalists act as catalysts to the subsequent discussion, inviting the participants to reflect on different aspects of the reconstruction policies associated with the Terceira, 1980 and the Faial, 1998 earthquakes, and on the post-1980 economic and social situation on the affected islands. During the discussion, and as a general conclusion, it was recommended that in meetings that deal with natural and technological risks, politicians, decision makers and other players of the society, besides scientists and technicians, should be involved in such forum, and keep them with a broader approach to keep the interest of the general public.

Several discussions, during the conference, pointed out the need to develop an Earthquake Early Warning System (EEWS) in Portugal including the Azores, for both the shaking and tsunami. In order to fulfill its function, the EEWS needs to detect earthquakes and determine some of their characteristics, including location and magnitude, before the effects of strong earthquakes and tsunami waves reach critical areas, so that protection measures can be decided and implemented prior to the event. The EEWS for shaking can enable automatic safety mechanisms to be activated in critical installations, such as gas pipelines, high-speed trains, bridges, tunnels, etc., minimizing the losses associated with the earthquake. For tsunami warning tens of minutes can be anticipated enabling the population to evacuate to higher locations previously established. This topic can be an excellent issue for an upcoming international congress.

\section{Acknowledgments:}

The authors would like to thank the following institutions: Instituto Superior Técnico (IST), Universidade dos Açores and Universidade de Évora. A special thanks to the Civil Engineering Research and Innovation for Sustainability (CERIS) and Associação para a Formação e o Desenvolvimento em Engenharia Civil e Arquitetura (FUNDEC) for videoconferencing support and logistics. This work is co-funded by national funds through FCT - Fundação para a Ciência e a Tecnologia, I.P., under projects Refas UIDB/04683/2020 e UIDP/04683/2020.

\section{References:}

Correia, J.R., Firmo, J.P., Gonilha, J., Garrido, M., Souza, M., Martins, D. Proença, M. (2020). Composite Materials for Civil Engineering Structures - Potential Use in Seismic Areas. International Meeting 40 Years of the 1980 Azores Earthquake, online meeting, 6-7 October 2020, 21-25. Retrieved from https://azores4080meeting.files.wordpress.com/2020/10/proceedingsbook-1.pdf

Ferreira A.M.G., Marignier, A., Attanayake, J., Frietsch, M., Berbellini, A., Vales, D., Carrilho, F. (2020a). Crustal structure and earthquakes in the Azores Archipelago: complex faulting, magmatic perturbations and underplating. International Meeting 40 Years of the 1980 Azores Earthquake, online meeting, 6-7 October 2020, 11-15. Retrieved from https://azores4080meeting.files.wordpress.com/2020/10/proceedingsbook-1.pdf

Ferreira A.M.G., Marignier, A., Attanayake, J., Frietsch, M., Berbellini, A. (2020b). Crustal structure of the Azores Archipelago from Rayleigh wave ellipticity data, Geophysical Journal International, $221(2), 1232-1247$. 
Fontiela, J., Rosset, P., Wyss, M., Bezzeghoud, M., Borges, J. F., Cota Rodrigues, F. (2020). Human Losses and Damage Expected in Future Earthquakes on Faial Island-Azores. Pure and Applied Geophysics, 177, 1831-1844.

Hamak I, Wachilala, P., Borges, J., Dias, N. A., Rio, I., Bezzeghoud, M. (2020). Three-dimensional crustal image of Arraiolos aftershock sequence, earthquake of $\mathrm{M}=4.9$, in Alentejo region, Portugal. International Meeting 40 Years of the 1980 Azores Earthquake, online meeting, 6-7 October 2020, 58-62. Retrieved from https://azores4080meeting.files.wordpress.com/2020/10/proceedingsbook1.pdf

Marreiros, C., Alves, P. Carrilho, F. (2020). The macroseismic questionnaire "Did you feel an earthquake?" and its automatic evaluation. International Meeting 40 Years of the 1980 Azores Earthquake, online meeting, 6-7 October 2020, 40-43. Retrieved from https://azores4080meeting.files.wordpress.com/2020/10/proceedingsbook-1.pdf

Matias, L., Carrilho, F., Omar, Y., Sá. V., Niehus, M., Corela, C., Barros, J. (2020). Improving the monitoring of offshore earthquakes in the Azores using optical fiber cables. International Meeting 40 Years of the 1980 Azores Earthquake, online meeting, 6-7 October 2020, 16-20. Retrieved from https://azores4080meeting.files.wordpress.com/2020/10/proceedingsbook-1.pdf

Morais, E.C., Ferreira, T.M., Estevão, J.C., Oliveira, C.S. (2020). An approach for the estimation of the magnitude of historical earthquakes: a sensitivity study of the 1980 and 1998 earthquakes in the Azores. International Meeting 40 Years of the 1980 Azores Earthquake, online meeting, 6-7 October 2020, 40-43. Retrieved from https://azores4080meeting.files.wordpress.com/2020/10/proceedingsbook-1.pdf

Oliveira, C.S. and Ferreira, M.A. (2020). 40 years after the 1980 Azores earthquake: impacts and learning. International Meeting 40 Years of the 1980 Azores Earthquake, online meeting, 6-7 October 2020, 7-10. Retrieved from https://azores4080meeting.files.wordpress.com/2020/10/proceedingsbook-1.pdf

Rosset P, J. Fontiela and M. Wyss, 2020. Seismic risk scenarios in Faial island, Azores, using QLARM. 40 years after the 1980 Azores earthquake: impacts and learning. International Meeting 40 Years of the 1980 Azores Earthquake, online meeting, 6-7 October 2020, 91-94. Retrieved from https://azores4080meeting.files.wordpress.com/2020/10/proceedingsbook-1.pdf

Silva, V. (2020a). Potential Impact of Earthquakes during the 2020 COVID-19 Pandemic in Portugal. International Meeting 40 Years of the 1980 Azores Earthquake, online meeting, 6-7 October 2020, 26-30. Retrieved from https://azores4080meeting.files.wordpress.com/2020/10/proceedingsbook1.pdf

Silva, V., Paul, N. (2020). Potential impact of earthquakes during the 2020 COVID-19 pandemic. Earthquake Spectra. https://doi.org/10.1177/8755293020950328

Udías A. and Buforn, E. (2020). Seismotectonics of Azores-Gibraltar: A review. International Meeting 40 Years of the 1980 Azores Earthquake, online meeting, 6-7 October 2020, 36-39. Retrieved from https://azores4080meeting.files.wordpress.com/2020/10/proceedingsbook-1.pdf 